\title{
Video Article \\ Generation of Induced Pluripotent Stem Cells by Reprogramming Mouse Embryonic Fibroblasts with a Four Transcription Factor, Doxycycline Inducible Lentiviral Transduction System
}

\author{
Brad Hamilton ${ }^{1}$, Qiang Feng ${ }^{1}$, Mike $\mathrm{Ye}^{1}, \mathrm{G}$ Grant Welstead ${ }^{2}$ \\ ${ }^{1}$ Stemgent \\ ${ }^{2}$ Whitehead Institute for Biomedical Research, MIT - Massachusetts Institute of Technology \\ Correspondence to: Brad Hamilton at brad.hamilton@stemgent.com
}

URL: https://www.jove.com/video/1447

DOI: doi:10.3791/1447

Keywords: Developmental Biology, Issue 33, reprogramming, Doxycycline, DOX, iPS, induced pluripotent stem cells, lentivirus, pluripotency, transduction, stem cells

Date Published: 11/13/2009

Citation: Hamilton, B., Feng, Q., Ye, M., Welstead, G.G. Generation of Induced Pluripotent Stem Cells by Reprogramming Mouse Embryonic Fibroblasts with a Four Transcription Factor, Doxycycline Inducible Lentiviral Transduction System. J. Vis. Exp. (33), e1447, doi:10.3791/1447 (2009).

\section{Abstract}

Using a defined set of transcription factors and cell culture conditions, Yamanaka and colleagues demonstrated that retrovirus-mediated delivery and expression of Oct4, Sox2, c-Myc, and Klf4 is capable of inducing pluripotency in mouse fibroblasts. ${ }^{1}$ Subsequent reports have demonstrated the utility of the doxycycline (DOX) inducible lentiviral delivery system for the generation of both primary and secondary iPS cells from a variety of other adult mouse somatic cell types. ${ }^{2,3}$

Induced pluripotent stem (iPS) cells are similar to embryonic stem (ES) cells in morphology, proliferation and ability to induce teratoma formation. Both types of cell can be used as the pluripotent starting material for the generation of differentiated cells or tissues in regenerative medicine.$^{4-6}$ iPS cells also have a distinct advantage over ES cells as they exhibit key properties of ES cells without the ethical dilemma of embryo destruction.

Here we demonstrate the protocol for reprogramming mouse embryonic fibroblast (MEF) cells with the Stemgent DOX Inducible Mouse TF Lentivirus Set. We also demonstrate that the Stemgent DOX Inducible Mouse TF Lentivirus Set is capable of expressing each of the four transcription factors upon transduction into MEFs thereby inducing a pluripotent stem cell state that displays the pluripotency markers characteristic of ES cells.

\section{Video Link}

The video component of this article can be found at https://www.jove.com/video/1447/

\section{Protocol}

\section{Viral Transduction of MEFs}

1. The day before beginning your experiment, coat a $15 \mathrm{~cm}$ cell culture dish with $0.2 \%$ gelatin sterile filtered in ddH $\mathrm{H}_{2} \mathrm{O}$. Incubate the plate overnight at $37^{\circ} \mathrm{C}$ and $5 \% \mathrm{CO}_{2}$.

2. Aspirate the liquid from the gelatin coated dish, and seed MEF cells (we used Nanog-GFP/rtTA MEF cells) at a density of $4 \times 10^{5}$ cells per dish. Incubate the cells in $30 \mathrm{ml}$ of MEF growth medium (450ml DMEM supplemented with $50 \mathrm{ml} \mathrm{FBS,} 5$ ml 100x non-essential amino acids, $5 \mathrm{ml}$ penicillin/streptomycin, $5 \mathrm{ml} 200 \mathrm{mM} \mathrm{L}$-glutamine and $0.5 \mathrm{ml} 55 \mathrm{mM} \beta$-mercaptoethanol) for two days at $37^{\circ} \mathrm{C}$ and $5 \% \mathrm{CO}_{2}$ until approximately $80 \%$ confluent.

3. Aspirate the medium and add $30 \mathrm{ml}$ of MEF growth medium supplemented with concentrated lentivirus $(4 \times 100 \mu \mathrm{l}$ virus stock solution +29.6 $\mathrm{ml}$ growth medium). Rock the dish gently to ensure even distribution of the medium. Incubate the cells overnight at $37^{\circ} \mathrm{C}$ and $5 \% \mathrm{CO}_{2}$.

\section{Doxycycline Induced Reprogramming}

1. 20-24 hours post-transduction, trypsinize the transduced cells, centrifuge at $200 \mathrm{xg}$ for 5 minutes and resuspend in ES/iPS growth medium (450 ml Knockout DMEM supplemented with $50 \mathrm{ml}$ ES cell-qualified calf serum, $5 \mathrm{ml}$ penicillin/streptomycin, $5 \mathrm{ml} 200 \mathrm{mM} \mathrm{L-glutamine,} 0.5$ $\mathrm{ml} \beta$-mercaptoethanol and $25 \mu \mathrm{LIF}$ ). Seed transduced MEF's at an appropriate concentration for the cell culture dish size (we used $2.5 \mathrm{x}$ $10^{5}$ cells per $10 \mathrm{~cm}$ dish for reprogramming efficiency experiments and colony isolation, and $2 \times 10^{4}$ cells per well in 4 well plates for ICC experiments). Incubate overnight at $37^{\circ} \mathrm{C}$ and $5 \% \mathrm{CO}_{2}$. Note: any remaining transduced cells can be frozen in liquid nitrogen for future analysis. 
2. Aspirate the medium and replace with ES/iPS medium prepared fresh and supplemented with doxycycline to a final concentration of $2 \mu \mathrm{g} / \mathrm{ml}$ (we also added medium without DOX as a negative control). Incubate at $37^{\circ} \mathrm{C}$ and $5 \% \mathrm{CO}_{2}$.

\section{Immunocytochemical Analysis of Transduction Efficiency}

48 hours post-doxycycline induction, determine transduction efficiency by immunohistochemistry(ICC). Carry out ICC testing on cells replated in

4 well plates. All volumes listed in the following protocol should be adjusted according to the cell culture plate size.

1. Wash the cells gently once with PBS (without $\mathrm{Mg}^{2+}+$ or $\mathrm{Ca}^{2+}$ ).

2. Fix the cells with $500 \mu \mathrm{l}$ of $0.5 \mathrm{ml} 4 \%$ paraformaldehyde in PBS for 15 minutes at room temperature.

3. Wash the cells gently two times with PBS.

4. Permeabilize cells by adding $500 \mu$ l of ice-cold $0.2 \%$ Tween®-20 in PBS. Incubate for 10 minutes at room temperature.

5. Wash the cells gently two times with PBS.

6. Block non-specific binding with $200 \mu$ l blocking buffer for one hour at room temperature.

7. Incubate the cells with $200 \mu \mathrm{l}$ of the specific primary antibody overnight at $4^{\circ} \mathrm{C}$ (we used Oct4, Klf4, Sox 2 and c-Myc).

8. Wash the cells gently two times with PBS.

9. Incubate the cells with $200 \mu$ of secondary antibody for 1 hour at room temperature, protecting the plates from light (we used Donkey antiRabbit Rhodamine conjugate, Donkey anti-Goat AlexaFluor ${ }^{8} 594$ conjugate, Donkey anti-Mouse Rhodamine conjugate and Donkey antiRabbit Rhodamine conjugate).

10. Wash the cells gently two times with PBS.

11. Add DAPI (final concentration $2 \mu \mathrm{g} / \mathrm{ml}$ in PBS) and incubate 10 minutes to visualize nuclei.

12. Wash the cells gently with PBS.

13. Add anti-fade Aqua-Mount before imaging using an inverted fluorescent microscope.

\section{Isolating and expanding iPS Cell Colonies}

1. After initiating the reprogramming process (as described in section 2), monitor the cultures and replace medium every 48 hours. We used doxycycline containing medium to culture the cells for the first twelve days and then subsequently removed doxycycline from the medium to ensure that the iPS colonies manually picked for expansion would be DOX independent.

2. Cells should be monitored daily for morphological changes indicative of the reprogramming process; or when using cells like Nanog-GFP/ rtTA MEF, monitor morphology and GFP fluorescence to identify reprogrammed colonies. Each experiment will be different, but colonies are generally large enough for isolation between 16 and 22 days. Colonies identified during this time frame can then be manually isolated and trypsinized for expansion and analysis.

3. The day before isolating and trypsinizing the reprogrammed colonies, prepare a 24-well plate by seeding with gamma-irradiated feeder layer MEFs at a density of $5 \times 10^{4}$ cells per well. Incubate overnight at $37^{\circ} \mathrm{C}$ and $5 \% \mathrm{CO}_{2}$.

4. Manually pick each iPS colony and trypsinize to dissociate the cell aggregates. Re-plate the iPS cells in ES/iPS medium in individual wells of the 24-well plate pre-seeded with gamma-irradiated feeder layer MEFs. Wells should be seeded at a density of $2 \times 10^{5}$ cells/well. Incubate at $37^{\circ} \mathrm{C}$ and $5 \% \mathrm{CO}_{2}$. Change media every 24 hours.

5. Monitor iPS colonies daily for growth and GFP fluorescence. We incubate our cultures for 6 days before passaging.

6. Determine which wells of the 24-well plate are uniformly expressing GFP. Wells that have good GFP expression can be trypsinized and passaged 1:8 into 4-well plates that have been pre-seeded with gamma-irradiated feeder layer MEFs. These plates can be used for pluripotent marker analysis by ICC and AP staining.

\section{Immunocytochemical Analysis for Pluripotency}

Our ICC testing was carried out on cells expanded in 4 well plates. All volumes listed in the following protocol should be adjusted according to the cell culture plate size.

1. Wash the cells gently twice with $\mathrm{PBS}$ (without $\mathrm{Mg}^{2+}+$ or $\mathrm{Ca}^{2+}$ ).

2. Incubate in $0.5 \mathrm{ml}$ of ice-cold $0.2 \%$ Tween 20 in PBS per well for 10 minutes.

3. Wash the cells gently three times with PBS.

4. Block non-specific binding with $200 \mu$ l blocking buffer for one hour at room temperature.

5. Incubate the cells with $200 \mu \mathrm{l}$ of the specific primary antibody overnight at $4^{\circ} \mathrm{C}$ (we used SSEA-1, Nanog and Oct4).

6. Wash the cells gently two times with PBS.

7. Incubate the cells with $200 \mu \mathrm{l}$ of secondary antibody for 1 hour at room temperature, keeping away from light (we used Donkey anti-Mouse Rhodamine conjugate and Donkey anti-Rabbit Rhodamine conjugate).

8. Wash the cells gently two times with PBS.

9. Add DAPI (final concentration $2 \mu \mathrm{g} / \mathrm{ml}$ in PBS) and incubate 10 minutes to visualize nuclei.

10. Wash the cells gently with PBS

11. Add anti-fade Aqua-Mount before imaging using an inverted fluorescent microscope.

\section{Alkaline Phosphatase (AP) Staining of iPS Cell Colonies}

1. iPS colonies from section 4 can also be analyzed for AP activity utilizing commercially available kits and following the manufacturer's protocol. 


\section{Part 7. Representative Results}

The Stemgent DOX Inducible Mouse TF Lentivirus Set can be used to reprogram MEFs to iPS cells. After transduction of the MEFs, expression of transcription factors Oct4, Sox2, KIf4 and c-Myc can be detected in cells treated with doxycycline (DOX+), but little or no expression can be detected in untreated (DOX-) cells (figure 1). Morphological changes will progress over time (12 days of DOX treatment in this example) to generate larger, more ES cell-like colonies with defined colony edges and three dimensional growth (figure 2a). When DOX is removed, there is a noticeable reversion of cellular morphology for some ES cell-like colonies, however, many of the colonies maintained their iPS morphology (figure 2a). These iPS colonies, when picked and passaged, display typical pluripotency marker expression of Alkaline Phosphatase (AP), Nanog, Oct4 and SSEA-1 (figure 3). The type of MEF cells used in this experiment (Nanog-GFP/rtTA MEF cells) express GFP from the endogenous Nanog locus when reprogrammed to the pluripotency state. GFP expression can therefore be used as a preliminary indicator for successful reprogramming (figure 3 ).

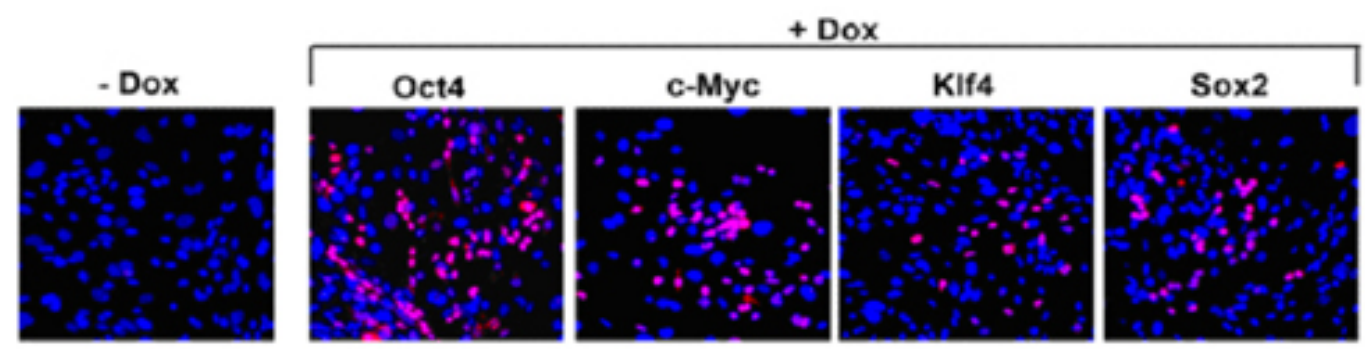

Figure 1: Immunocytochemistry (ICC) analysis 48 hours post-DOX induction. The far left panel (-DOX) is a representative negative control for expression of the four transduction factors without DOX induction. Correctly expressed transcription factors were confirmed by corresponding antibodies (shown in red), stained with DAPI to visualize the nucleus. 

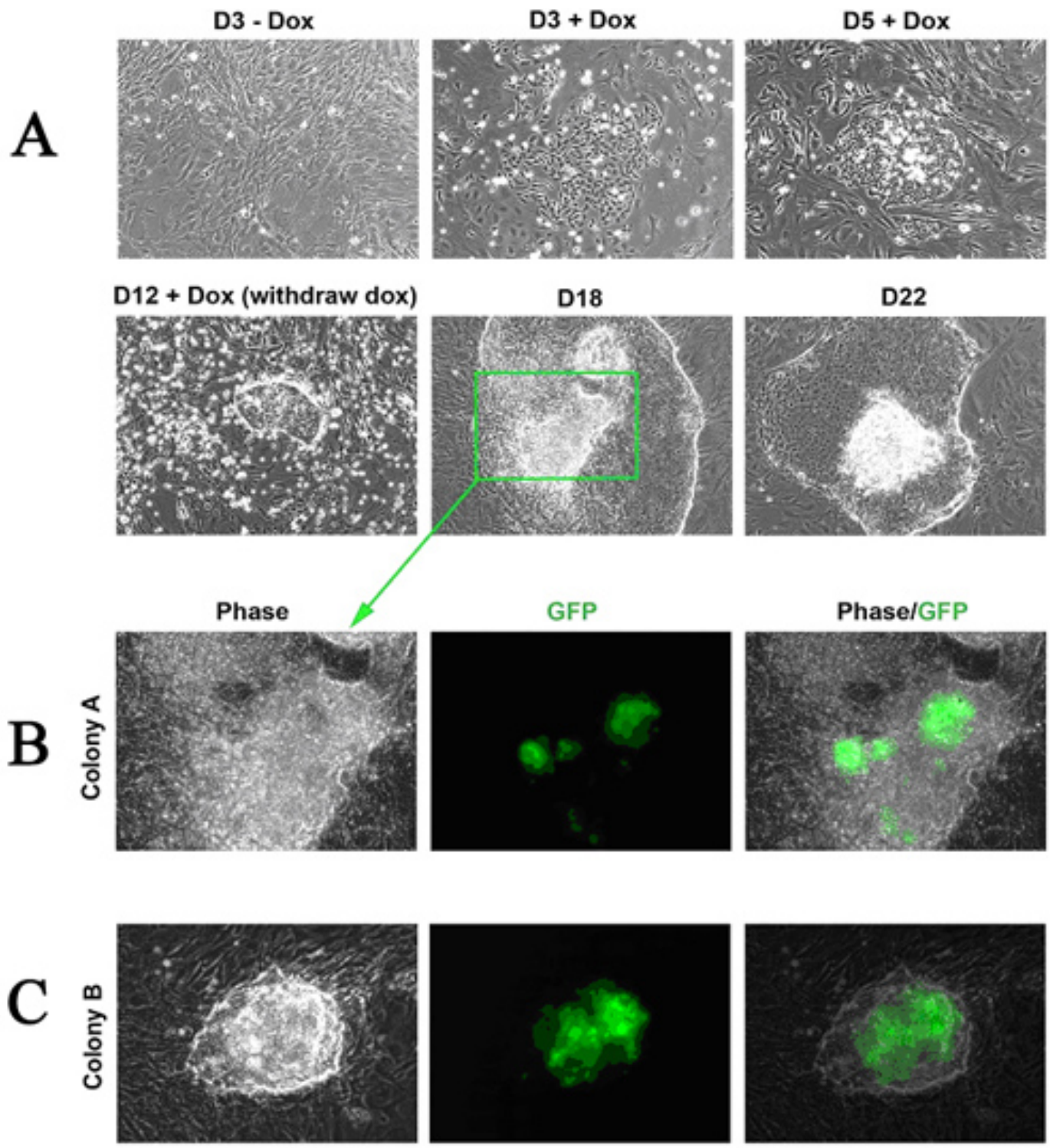

Figure 2: Morphological conversion of Nanog-GFP/rtTA MEFs to the iPS cell state. A) 100x phase contrast imaging of cells demonstrating the compaction and conversion of MEFs into iPS colonies over time from day 3 (D3+Dox) to day 22 (D22). DOX was withdrawn on day 12. Upper left panel: 20x negative control image from -DOX plate. B) 200x phase-contrast and GFP fluorescence images of highlighted day 18 post-DOX induction iPS colony. C) $200 x$ phase-contrast and GFP fluorescence images of additional day 18 post-DOX induction iPS colony. 

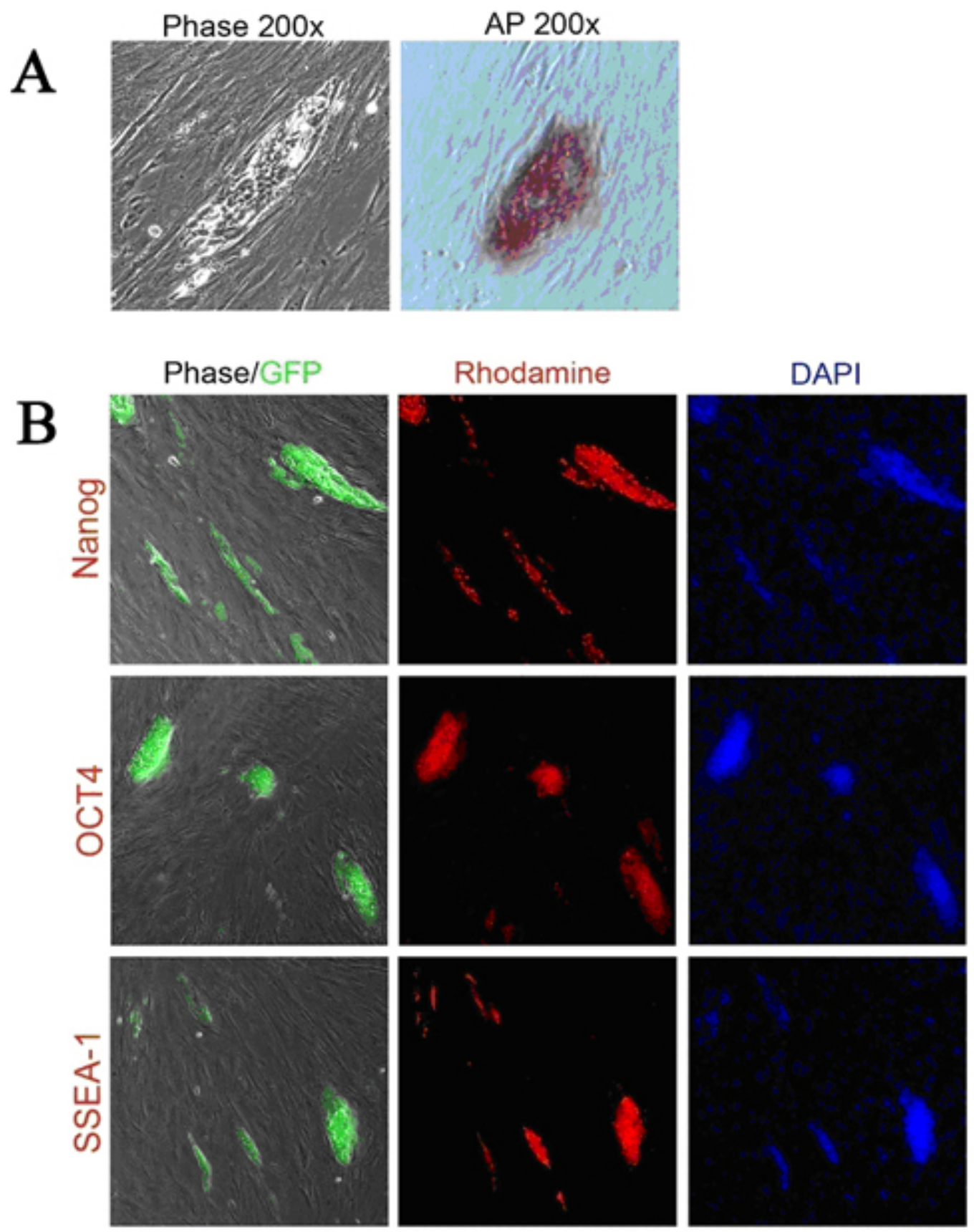

Figure 3: Analysis of iPS colonies. (A) Phase contrast microscopy and AP staining of an iPS colony (200x). (B) Pluripotency marker analysis: Left panel shows phase contrast overlay with GFP reprogramming reporter expression. GFP expression reflects the endogenous Nanog expression level. Middle panel shows ICC staining for pluripotency markers. Right panel shows DAPI staining to visualize the nuclei (100x).

\section{Discussion}

These results demonstrate that the Stemgent DOX Inducible Mouse TF Lentivirus Set can be used to efficiently generate iPS colonies by inducing the ectopic expression of transduced transcription factors in mouse embryonic fibroblasts. When designing reprogramming experiments, several variables should be considered to optimize the efficiency of reprogramming. First, it is possible to modify the active virusto-target cell ratio (i.e. M.O.I.) during the primary infection step to increase or decrease the transduction efficiency, thereby affecting the number of integrated viruses in the target cell population. Second, adjusting the length of time the cells are exposed to DOX can affect the efficiency of iPS cell colony generation. Third, the proliferative capacity of the target cells can impact reprogramming, as cells which are actively growing and dividing are more amenable to reprogramming. Lastly, when modifying the protocol for different cell numbers or different size tissue culture dishes, it is recommended that target cell numbers be adjusted proportionally to the surface area of the culture dish. 


\section{Disclosures}

The author, Brad Hamilton, is employed by Stemgent that produces reagents and instruments used in this article.

\section{References}

1. Takahashi, K. \& Yamanaka, S. Induction of pluripotent stem cells from mouse embryonic and adult fibroblast cultures by defined factors. Cell 126, 663-676 (2006).

2. Aoi, T., Yae, K., Nakagawa, M., Ichisaka, T., Okita, K., Takahashi, K., Chiba, T. \& Yamanaka, S. Generation of pluripotent stem cells from adult mouse liver and stomach cells. Science 321, 699-702 (2008).

3. Yu, J., Vodyanik, M.A., Smuga-Otto, K., Antosiewicz-Bourget, J., Frane, J.L., Tian, S., Nie, J., Jonsdottir, G.A., Ruotti, V., Stewart, R., Slukvin, I.I. \& Thomson, J.A. Induced pluripotent stem cell lines derived from human somatic cells. Science 318, 1917-1920 (2007).

4. Murry, C.E. \& Keller, G. Differentiation of embryonic stem cells to clinically relevant populations: lessons from embryonic development. Cell $132,661-680$ (2008).

5. Lerou, P.H. \& Daley, G.Q. Therapeutic potential of embryonic stem cells. Blood Rev. 19, 321-331 (2005).

6. Wernig, M., Meissner, A., Foreman, R., Brambrink, T., Ku, M., Hochedlinger, K., Bernstein, B.E. \& Jaenisch, R. In vitro reprogramming of fibroblasts into a pluripotent ES-cell-like state. Nature 448, 318-324 (2007). 